ORIGINAL ARTICLE

\title{
Impact of smoking on mortality of patients with non-small cell lung cancer
}

\author{
Seung Jun Lee 1,2, Jinwoo Lee ${ }^{1}$, Young Sik Park', Chang-Hoon Lee', Sang-Min Lee', Jae-Joon Yim', \\ Chul-Gyu Yoo', Sung Koo Han¹ \& Young Whan Kim¹ \\ 1 Division of Pulmonary and Critical Care Medicine, Department of Internal Medicine and Lung Institute, Seoul National University College of Medicine, \\ Seoul, Korea \\ 2 Division of Pulmonary and Critical Care Medicine, Department of Internal Medicine, Gyeongsang National University Hospital, Jinju, Korea
}

\author{
Keywords \\ Mortality; non-small cell lung cancer; risk \\ factors; smoking.

\section{Correspondence \\ Young Whan Kim, Division of Pulmonary and Critical Care Medicine, Departmentof Internal Medicine and Lung Institute of Medical Research Center, Seoul National University Seoul 110-744, Korea. \\ Tel: +82220722856 \\ Fax: +8227629662 \\ Email: ywkim@snu.ac.kr} \\ College of Medicine, 101Daehak-ro, Jongno-gu,
}

Received: 9 February 2013;

accepted 24 April 2013.

doi: $10.1111 / 1759-7714.12051$

\begin{abstract}
Background: Cigarette smoking is one of the major causes of lung cancer. However, the correlation between smoking status and the survival of patients with lung cancer is uncertain. The present study aimed to evaluate the impact of smoking status on the mortality of patients with non-small cell lung cancer (NSCLC).

Methods: The medical records of 313 patients newly diagnosed with NSCLC between January 2005 and January 2006 were reviewed. Eligible patients were divided into ever-smokers (221 patients) and never-smokers (92 patients), and the overall survival and clinical characteristics of the two groups were compared. Predictors of survival were analyzed using Cox's proportional hazards regression.

Results: In ever-smokers, the mean age was higher, and male gender and squamous histology were predominant compared to never-smokers. The median survival time was longer in never-smokers (21.1 vs. 41.9 months, ever-smokers vs. never-smokers, respectively; $\mathrm{P}=0.027$ ). Overall survival estimates at 12,24 , and 60 months were 62.9 versus $82.6 \%, 43.4$ versus $65.2 \%$, and 31.2 versus $42.4 \%$, in each group. Advanced age, advanced disease stage (stages III and IV), and coexistence of interstitial lung disease were analyzed as independent risk factors for shorter survival. Although eversmoking was not an independent risk factor, current smoking was a risk factor for higher mortality.

Conclusions: The overall mortality of ever-smokers was higher than that of neversmokers in patients with newly diagnosed NSCLC, and current smoking was an independent risk factor for a poorer prognosis.
\end{abstract}

\section{Introduction}

Lung cancer accounted for $12.7 \%$ ( 1.61 million) of all new cancers in 2008 globally, and was the most common type associated with cancer-related deaths. ${ }^{1,2}$ Cigarette smoking is a well-established cause of lung and many other types of cancer, including cancers of the oral cavity, pharynx, larynx, esophagus, stomach, colon, liver, pancreas, cervix, kidney, and lower urinary tract. ${ }^{3,4}$ Both current and past smoking significantly increases the relative risk of lung cancer. ${ }^{4}$ Furthermore, millions of deaths worldwide as a result of cardiovascular disease, chronic obstructive lung disease, and lung cancer, are attributable to cigarette smoking. ${ }^{5}$

Although a causal relationship between smoking and the incidence of lung cancer is clear, there have only been a few studies on the impact of smoking status on the mortality of patients with lung cancer, and the results have not always agreed. Ferketich et al. reported that current smokers at the time of diagnosis with non-small cell lung cancer (NSCLC) had poorer survival rates compared to never-smokers, in a population of 4200 patients who participated in the National Comprehensive Cancer Network project in the United States. ${ }^{6}$ Nia et al. reported that non-smokers, former smokers, and recent quitters had better survival rates than current smokers in 311 surgical patients with NSCLC in Belgium. ${ }^{7}$ Conversely, the study by Meguid et al. showed no difference in the long-term survival of patients with NSCLC between current- and never-smokers. ${ }^{8}$

In the present retrospective study, long-term mortality and the clinical characteristics of patients with NSCLC were 
evaluated according to smoking status at the time of diagnosis. Additionally, risk factors for overall mortality in NSCLC patients were identified.

\section{Methods}

\section{Data collection}

Information concerning patients' baseline demographics and clinical characteristics was determined by reviewing the medical records of enrolled subjects. Age, gender, body mass index (BMI), smoking status, number of smoking pack-years, pulmonary function, Eastern Cooperative Oncology Group (ECOG) performance status, comorbidities, symptoms at presentation, tumor node metastasis (TNM) stage, histologic type of lung cancer, serum level of carcinoembryonic antigen (CEA), and method of treatment were obtained from medical records. Smoking status was categorized into: (i) neversmokers, patients who had never smoked or had smoked fewer than 100 cigarettes in their entire lifetime; (ii) formersmokers, patients who had smoked at least 100 cigarettes in their lifetime and had stopped smoking at least one month before the diagnosis of lung cancer; (iii) current-smokers, patients who continued smoking upon diagnosis or stopped smoking less than one month before the diagnosis of lung cancer and had smoked more than 100 cigarettes during their lifetime. The stage of lung cancer was graded according to the $7^{\text {th }}$ American Joint Committee on Cancer TNM classification. NSCLC histologic type was divided into adenocarcinoma, squamous cell carcinoma, NSCLC not otherwise specified, and others, which included large cell carcinoma, carcinoid tumor, signet ring carcinoma, and mucoepidermoid carcinoma. Review of medical records also identified the date of death. If the date of death could not be identified from medical records, data from the Korean Ministry of Public Administration and Security on 26 October 2012 was used. Follow-up for survival analysis was defined as the time in months from diagnosis of lung cancer to the date of death or the date of the last outpatient visit.

\section{Study population}

In total, 313 patients aged over 20 years and newly diagnosed with NSCLC histologically and/or cytologically between January 2005 and January 2006 at Seoul National University Hospital, Seoul, Korea were enrolled in the current study. Among them, 221 (70.6\%) patients were ever-smokers, and $92(29.4 \%)$ patients were never-smokers. Subjects were excluded if they had a malignant disease other than lung cancer that affected their survival $(n=2)$, the lung cancer presented as an incidentally found ground-glass nodule (GGN) $(\mathrm{n}=4)$, or smoking status could not be verified $(\mathrm{n}=$ 46). The Seoul National University Hospital Institutional
Review Board approved the study (approval number IRB-H1204-093-407). Eligible patients were divided into eversmokers, including current and former smokers, and neversmokers. Demographic and clinical characteristics, as well as overall survival, were compared between the groups. Additionally, risk factors for mortality of NSCLC patients were analyzed.

\section{Statistical analysis}

Comparison of continuous variables, including age, BMI, number of smoking pack-years, pulmonary function, and serum CEA level, was performed by unpaired $t$-test between two groups or one-way analysis of variance (ANOVA) between three groups. Categorical variables, including gender, ECOG status, stage of lung cancer, histology, method of treatment, symptoms, and comorbidities were analyzed using Pearson's chi-squared test. The survival of patients was evaluated using Kaplan-Meier survival curves, and the difference was assessed by the log-rank test. The Cox proportional hazards model was used to estimate independent risk factors for the mortality of patients after adjusting for significant confounding factors. Variables with a $\mathrm{P}<0.05$ in a univariate analysis were entered into a multivariate analysis. Hazard ratios (HRs) and 95\% confidence intervals (CIs) were estimated. Differences were deemed to be statistically significant at $\mathrm{P}<0.05$. Statistical analyses were performed using SPSS version 18.0 for Windows (SPSS Inc., Chicago, IL, USA).

\section{Results}

\section{Demographic and clinical characteristics}

Ever-smokers were significantly older than never-smokers (mean ages, 64.7 and 57.6 years, respectively; $\mathrm{P}<0.001$ ). Male patients accounted for $96.8 \%$ of ever-smokers, in contrast to the $85.9 \%$ female predominance in never-smokers. The ratio of forced expiratory volume in 1 second $\left(\mathrm{FEV}_{1}\right)$ /forced vital capacity (FVC) and predicted $\%$ of $\mathrm{FEV}_{1}$ were significantly lower in ever-smokers. About $67 \%$ of ever-smokers and $62 \%$ of never-smokers had stage III or IV disease. Interestingly, the proportion of patients with stage IV lung cancer was higher in never-smokers than in ever-smokers $(46.7 \%$ vs. $32.1 \%$, respectively). Squamous cell was the most common histologic type in ever-smokers, whereas adenocarcinoma was the most common histologic type in never-smokers. Surgical resection was the most commonly performed treatment in both groups, followed by chemotherapy. BMI, ECOG performance status, and serum CEA level were comparable in the two groups (Table 1).

Cough was the most common symptom at presentation in both groups. Sputum and dyspnea were significantly more common in ever-smokers than in never-smokers. The 
Table 1 Baseline characteristics of the study population

\begin{tabular}{|c|c|c|c|c|}
\hline & \multicolumn{2}{|c|}{ Ever-smokers $(n=221)$} & \multirow[b]{2}{*}{$\begin{array}{l}\text { Never-smokers } \\
(\mathrm{n}=92)\end{array}$} & \multirow[b]{2}{*}{ P-value } \\
\hline & $\begin{array}{l}\text { Current-smokers } \\
(n=96)\end{array}$ & $\begin{array}{l}\text { Former-smokers } \\
(n=125)\end{array}$ & & \\
\hline Age, year & $62.7 \pm 8.5$ & $66.2 \pm 10.1$ & $57.6 \pm 10.4$ & $<0.001$ \\
\hline Male $\%$ / female $\%$ & $99.0 / 1.0$ & $95.2 / 4.8$ & $14.1 / 85.9$ & $<0.001$ \\
\hline $\mathrm{BMI}, \mathrm{kg} / \mathrm{m}^{2}$ & $22.1 \pm 3.4$ & $22.5 \pm 3.0$ & $23.0 \pm 3.0$ & 0.095 \\
\hline Pack-years & $39.0 \pm 15.8$ & $39.0 \pm 19.9$ & 0 & $<0.001$ \\
\hline $\mathrm{FEV}_{1} / \mathrm{FVC}, \%$ & $66.1 \pm 12.7$ & $67.5 \pm 11.7$ & $79.1 \pm 5.2$ & $<0.001$ \\
\hline $\mathrm{FEV}_{1}, \mathrm{~L}$ & $2.1 \pm 0.6$ & $2.3 \pm 0.7$ & $2.1 \pm 0.6$ & 0.167 \\
\hline $\mathrm{FEV}_{1}, \%$ & $77.3 \pm 18.5$ & $86.1 \pm 22.2$ & $96.9 \pm 23.6$ & $<0.001$ \\
\hline FVC, L & $3.2 \pm 0.8$ & $3.3 \pm 0.8$ & $2.6 \pm 0.8$ & $<0.001$ \\
\hline FVC, \% & $82.8 \pm 16.1$ & $88.4 \pm 15.9$ & $89.8 \pm 21.5$ & 0.0127 \\
\hline ECOG status & & & & 0.692 \\
\hline $0-1$ & $91(94.8)$ & $118(94.4)$ & $88(95.7)$ & \\
\hline$\geq 2$ & $5(5.2)$ & $7(5.6)$ & $4(4.3)$ & \\
\hline Stage & & & & 0.001 \\
\hline 1 & $18(18.8)$ & $26(20.8)$ & $27(29.3)$ & \\
\hline$\|$ & $13(13.5)$ & $16(12.8)$ & $8(8.7)$ & \\
\hline III & $35(36.5)$ & $42(33.6)$ & $14(15.2)$ & \\
\hline IV & $30(31.3)$ & $41(32.8)$ & $43(46.7)$ & \\
\hline Histology & & & & $<0.001$ \\
\hline Adenocarcinoma & $23(24.0)$ & $46(36.8)$ & $75(81.5)$ & \\
\hline Squamous cell & $47(49.0)$ & $49(39.2)$ & $2(2.2)$ & \\
\hline NSCLC, NOS & $18(18.8)$ & $25(20.0)$ & $12(13.0)$ & \\
\hline Others & $8(8.3)$ & $5(4.0)$ & $3(3.3)$ & \\
\hline Treatment & & & & 0.039 \\
\hline Surgery & $40(41.7)$ & $52(41.6)$ & $43(46.7)$ & \\
\hline Chemotherapy & $36(37.5)$ & $42(33.6)$ & $42(45.7)$ & \\
\hline Chemoradiation & $4(4.2)$ & $8(6.4)$ & $0(0)$ & \\
\hline Radiation & $5(5.2)$ & $5(4.0)$ & $2(2.2)$ & \\
\hline BSC & $7(7.3)$ & $16(12.8)$ & $4(4.3)$ & \\
\hline Unknown & $4(4.2)$ & $2(1.6)$ & $1(1.1)$ & \\
\hline Serum level of CEA, ng/ml & $20.6 \pm 137.4$ & $74.9 \pm 436.1$ & $25.4 \pm 114.8$ & 0.477 \\
\hline
\end{tabular}

Values are presented as mean \pm standard deviation or No. (\%). P-values represent differences between ever- and never-smokers. BMI, body mass index; BSC, best supportive care; CEA, carcinoembryonic antigen; ECOG, Eastern Cooperative Oncology Group; FEV forced expiratory volume in 1 second; FVC, forced vital capacity; NOS, not otherwise specified; NSCLC, non-small cell lung cancer.

number of asymptomatic patients was greater in neversmokers (Table 2). Hypertension was the most common comorbid disease in both groups and was more common in ever-smokers (Table 2).

\section{Comparison of survival between ever-smokers and never-smokers}

Two hundred and twenty five out of 313 patients died and 88 patients survived during the study period. The median survival in the group of survivors was 84.0 months. The median survival time was 21.1 months in ever-smokers and 41.9 months in never-smokers (log-rank test; $\mathrm{P}=0.027$; Fig 1a). The median survivals for current and former smokers were 14.7 and 22.6 months, respectively. Kaplan-Meier survival estimates at 12,24 , and 60 months were 62.9 versus $82.6 \%$,
43.4 versus $65.2 \%$, and 31.2 versus $42.4 \%$, in each group, respectively. Kaplan-Meier survival curves of current, former, and never-smokers are shown in Figure $1 \mathrm{~b}$.

\section{Prognostic factors of survival in the study population}

Univariate analysis showed that ever-smokers, advanced age, male gender, low BMI, advanced disease stage (stage III and IV), low $\mathrm{FEV}_{1}$ (\% predicted), low FVC (\% predicted), a high serum CEA level, ECOG $\geq 2$, the presence of cough, sputum, dyspnea, extra-thoracic pain, hoarseness, and neurologic symptoms, and the coexistence of diabetes and interstitial lung disease (ILD) were predictors of high overall mortality. Advanced age, advanced disease stage (stage III and IV), and the coexistence of ILD were still significant predictors of high 
Table 2 Symptoms at presentation and comorbidities of enrolled patients

\begin{tabular}{|c|c|c|c|c|}
\hline & \multicolumn{2}{|c|}{ Ever-smokers $(n=221)$} & \multirow[b]{2}{*}{$\begin{array}{l}\text { Never-smokers } \\
(\mathrm{n}=92)\end{array}$} & \multirow[b]{2}{*}{ P-value } \\
\hline & $\begin{array}{l}\text { Current-smokers } \\
(\mathrm{n}=96)\end{array}$ & $\begin{array}{l}\text { Former-smokers } \\
(n=125)\end{array}$ & & \\
\hline \multicolumn{5}{|l|}{ Symptoms } \\
\hline Cough & $42(43.8)$ & $54(43.2)$ & $37(40.2)$ & 0.599 \\
\hline Sputum & $33(34.4)$ & $36(28.8)$ & $17(18.5)$ & 0.021 \\
\hline Dyspnea & $13(13.5)$ & $29(23.2)$ & $19(20.7)$ & 0.737 \\
\hline Hemoptysis & $17(17.7)$ & $26(20.8)$ & $8(8.7)$ & 0.019 \\
\hline Weight loss & $8(8.3)$ & $9(7.2)$ & $4(4.3)$ & 0.281 \\
\hline Thoracic pain & $14(14.6)$ & $11(8.8)$ & $10(10.9)$ & 0.910 \\
\hline Extra-thoracic pain & $6(6.3)$ & $4(3.2)$ & $7(7.6)$ & 0.273 \\
\hline Hoarseness & $5(5.2)$ & $3(2.4)$ & $3(3.3)$ & 0.875 \\
\hline Neurologic symptom & $4(4.2)$ & $3(2.4)$ & $1(1.1)$ & 0.288 \\
\hline Others & $2(2.1)$ & $2(1.6)$ & $0(0)$ & 0.194 \\
\hline Asymptomatic & $19(19.8)$ & $35(28.0)$ & $34(37.0)$ & 0.025 \\
\hline \multicolumn{5}{|l|}{ Comorbidities } \\
\hline COPD & $50(52.1)$ & $61(48.8)$ & $0(0)$ & $<0.001$ \\
\hline Hypertension & $17(17.7)$ & 37 (29.6) & $13(14.1)$ & 0.043 \\
\hline Diabetes & $8(8.3)$ & $21(16.8)$ & $7(7.6)$ & 0.164 \\
\hline Cardiovascular disease & $6(6.3)$ & $10(8.0)$ & $2(2.2)$ & 0.079 \\
\hline Malignant disease & $4(4.2)$ & $10(8.0)$ & $9(9.8)$ & 0.287 \\
\hline ILD & $3(3.1)$ & $6(4.8)$ & $2(2.2)$ & 0.406 \\
\hline Others & $7(7.3)$ & $7(5.6)$ & $2(2.2)$ & 0.128 \\
\hline No comorbidities & $64(66.7)$ & $60(48.0)$ & $66(71.7)$ & 0.010 \\
\hline
\end{tabular}

Values are presented as No. (\%). P-values represent for differences between ever- and never-smokers. COPD, chronic obstructive pulmonary disease; ILD, interstitial lung disease.

mortality after multivariate analysis (Table 3). Ever-smoking was a significant risk factor on univariate analysis, but eversmokers had no increase in mortality over never-smokers after adjusting for covariates. Otherwise, current smoking remained a significant prognostic factor after multivariate analysis compared with current non-smoking, including former and never smoking ( $\mathrm{HR}, 1.466 ; \mathrm{P}=0.032$; Table 4).

\section{Discussion}

The present study was conducted to evaluate the impact of smoking status at the time of diagnosis on the long-term overall survival of patients with NSCLC. The mortality of ever-smokers, including current and former smokers, was higher than that of never-smokers. After adjusting for

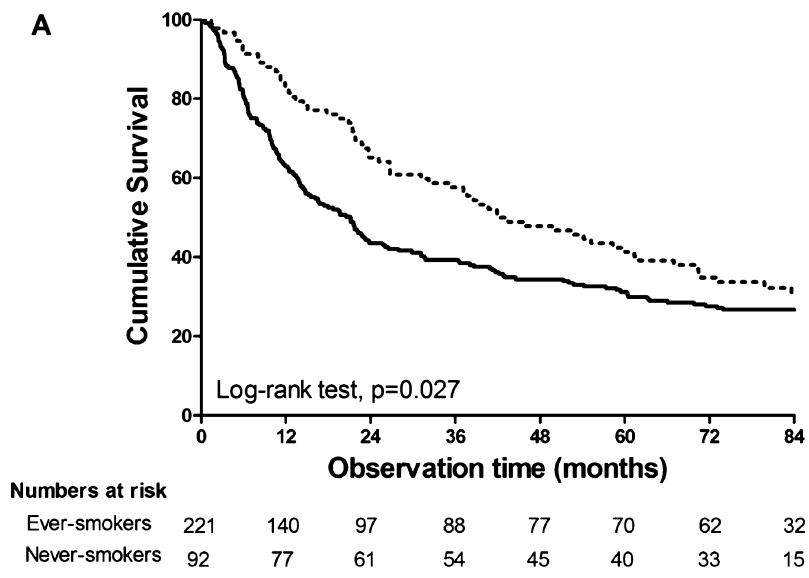

B

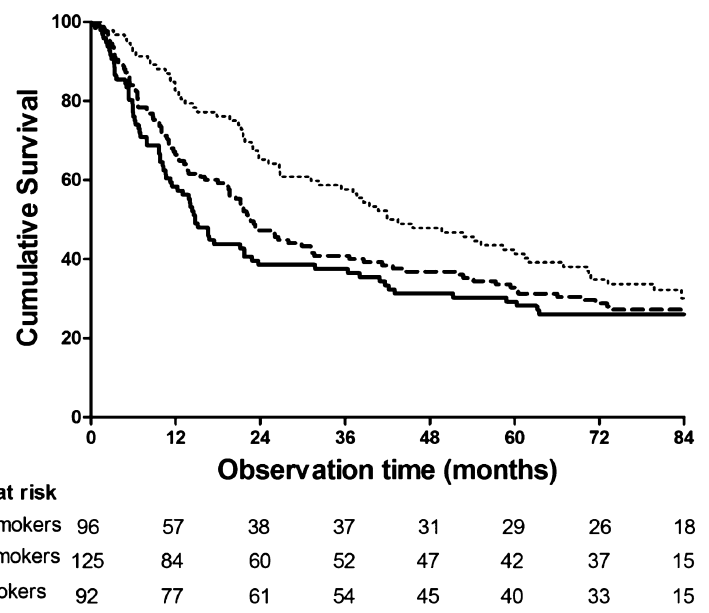

Figure 1 Overall survival of patients with non-small cell lung cancer (NSCLC) according to smoking status. (a) —, ever-smokers; - - - , never-smokers. (b) -, current-smokers.; --, former-smokers; ....., never-smokers. 
Table 3 Prognostic factors for higher overall mortality using univariate and multivariate analysis

\begin{tabular}{|c|c|c|c|c|c|c|}
\hline & \multicolumn{3}{|c|}{ Univariate analysis } & \multicolumn{3}{|c|}{ Multivariate analysis } \\
\hline & $H R$ & $95 \% \mathrm{Cl}$ & $p$-value & $H R$ & $95 \% \mathrm{Cl}$ & P-value \\
\hline \multicolumn{7}{|l|}{ Smoking status } \\
\hline Never-smokers & 1 & & & 1 & & \\
\hline Ever-smokers & 1.387 & $1.037-1.857$ & 0.028 & 0.810 & $0.458-1.403$ & 0.470 \\
\hline Current-smokers & 1.499 & 1.067 & 0.020 & 1.050 & $0.576-1.916$ & 0.873 \\
\hline Former-smokers & 1.311 & $0.951-1.809$ & 0.098 & 0.665 & $0.367-1.205$ & 0.179 \\
\hline Age, years & 1.036 & $1.022-1.050$ & $<0.001$ & 1.044 & $1.026-1.061$ & $<0.001$ \\
\hline \multicolumn{7}{|l|}{ Gender } \\
\hline Female & 1 & & & 1 & & \\
\hline Male & 1.471 & $1.089-1.987$ & 0.012 & 1.611 & $0.906-2.866$ & 0.104 \\
\hline $\mathrm{BMI}, \mathrm{kg} / \mathrm{m}^{2}$ & 0.944 & $0.904-0.986$ & 0.009 & 0.957 & $0.912-1.005$ & 0.076 \\
\hline \multicolumn{7}{|l|}{ Stage } \\
\hline I & 1 & & & 1 & & \\
\hline$\|$ & 1.555 & $0.853-2.838$ & 0.150 & 1.199 & $0.635-2.266$ & 0.576 \\
\hline III & 3.636 & $2.313-5.716$ & $<0.001$ & 3.082 & $1.919-4.951$ & $<0.001$ \\
\hline IV & 7.594 & 4.889-11.794 & $<0.001$ & 7.573 & $4.654-12.323$ & $<0.001$ \\
\hline †Adenocarcinoma & 0.808 & $0.621-1.051$ & 0.111 & & & \\
\hline ‡Squamous cell & 0.807 & $0.603-1.081$ & 0.150 & & & \\
\hline $\mathrm{FEV}_{1}, \%$ & 0.984 & $0.978-0.990$ & $<0.001$ & 0.991 & $0.976-1.006$ & 0.224 \\
\hline FVC, \% & 0.981 & $0.974-0.989$ & $<0.001$ & 1.004 & $0.987-1.020$ & 0.676 \\
\hline CEA, ng/ml & 1.001 & $1.000-1.001$ & 0.008 & 1.000 & $1.000-1.001$ & 0.165 \\
\hline \multicolumn{7}{|l|}{ ECOG status } \\
\hline $0-1$ & 1 & & & 1 & & \\
\hline$\geq 2$ & 2.686 & $1.587-4.548$ & $<0.001$ & 1.387 & $0.708-2.717$ & 0.340 \\
\hline Cough & 1.313 & $1.009-1.709$ & 0.042 & 1.020 & $0.683-1.523$ & 0.924 \\
\hline Sputum & 1.424 & $1.069-1.896$ & 0.01 & 0.850 & $0.555-1.302$ & 0.455 \\
\hline Dyspnea & 2.134 & $1.574-2.894$ & $<0.001$ & 1.080 & $0.709-1.645$ & 0.719 \\
\hline Hemoptysis & 1.275 & $0.899-1.808$ & 0.173 & & & \\
\hline Weight loss & 1.611 & $0.982-2.643$ & 0.059 & & & \\
\hline Thoracic pain & 1.241 & $0.835-1.844$ & 0.286 & & & \\
\hline Extra-thoracic pain & 2.013 & $1.191-3.405$ & 0.009 & 1.737 & $0.958-3.151$ & 0.069 \\
\hline Hoarseness & 2.210 & $1.170-4.173$ & 0.015 & 1.669 & $0.838-3.325$ & 0.145 \\
\hline Neurologic symptom & 3.669 & $1.795-7.500$ & $<0.001$ & 2.216 & $0.925-5.309$ & 0.074 \\
\hline COPD & 1.371 & $1.046-1.797$ & 0.022 & 0.985 & $0.590-1.647$ & 0.955 \\
\hline Hypertension & 1.162 & $0.854-1.581$ & 0.341 & & & \\
\hline Diabetes & 1.575 & $1.078-2.303$ & 0.019 & 1.079 & $0.702-1.658$ & 0.729 \\
\hline Cardiovascular disease & 1.319 & $0.768-2.267$ & 0.316 & & & \\
\hline Malignant disease & 0.702 & $0.409-1.207$ & 0.200 & & & \\
\hline ILD & 2.783 & $1.506-5.143$ & 0.001 & 2.529 & $1.272-5.030$ & 0.008 \\
\hline
\end{tabular}

tReferent histology for adenocarcinoma is non-adenocarcinoma. \#Referent histology for squamous cell is non-squamous cell carcinoma. CEA, carcinoembryonic antigen; $\mathrm{Cl}$, confidence interval; body mass index; COPD, chronic obstructive pulmonary disease; ECOG, Eastern Cooperative Oncology Group; FEV forced expiratory volume in 1 second; FVC, forced vital capacity; HR, hazard ratio; ILD, interstitial lung disease.

confounding variables, ever-smoking was not an independent prognostic factor. Current smoking increased mortality compared to current non-smoking, including never and former smoking, even after adjustment. Ever-smokers were significantly older, predominantly male, and had a higher frequency of squamous cell histology, whereas never-smokers were younger, predominantly female, and had a higher frequency of adenocarcinoma.

It is well established that smoking is a major cause of mortality from diverse medical diseases..$^{5,9,10}$ Of these, lung cancer is the third most common cause of death attributable to smoking (0.85 million deaths), with the highest fraction attributable to smoking $(71 \%)$ in the year $2000 .{ }^{10} \mathrm{With}$ respect to these deleterious impacts of smoking, there is a growing body of literature that evaluates the correlation between smoking and the survival of patients with lung cancer.

It seems obvious that smoking cessation improves the survival of patients with lung cancer. ${ }^{11-14}$ However, there is controversy concerning the impact of smoking status at the time of diagnosis on the survival of patients with lung cancer. The impact of smoking is usually assessed in terms of two aspects: (i) the difference in overall survival according to smoking status and (ii) the importance of smoking status as a prognostic factor after adjusting for confounders. The results of 
Table 4 Independent prognostic factors for higher mortality after multivariate analysis

\begin{tabular}{lllr}
\hline & $\mathrm{HR}$ & $95 \% \mathrm{Cl}$ & P-value \\
\hline $\begin{array}{lllr}\text { Smoking status } \\
\quad \text { Current non-smoking }\end{array}$ & 1 & & \\
$\quad$ Current smoking & 1.466 & $1.034-2.079$ & 0.032 \\
$\begin{array}{l}\text { Age, years } \\
\text { Stage }\end{array}$ & 1.044 & $1.028-1.061$ & $<0.001$ \\
I & 1 & & \\
II & 1.189 & $0.630-2.246$ & 0.593 \\
III & 3.000 & $1.869-4.816$ & $<0.001$ \\
IV & 8.149 & $4.980-13.334$ & $<0.001$ \\
ILD & 2.591 & $1.306-5.138$ & 0.006 \\
\hline
\end{tabular}

$\mathrm{Cl}$, confidence interval; $\mathrm{HR}$, hazard ratio; ILD, interstitial lung disease.

previous studies have varied widely. Nia et al. and Tammemagi et al. reported that current smokers had shorter survival rates than never- and former-smokers, and current smoking was an independent predictor of a poor prognosis. ${ }^{71}$ Similarly, in the recent report by Ferketich et al., current smokers had significantly poorer survival than neversmokers and current smoking was a poor prognostic factor. ${ }^{6}$ According to the report of Hanagiri et al., ever-smokers had worse survival than never-smokers; however, ever-smoking was not a prognostic factor in a multivariate analysis. ${ }^{16}$ In contrast, Toh et al. reported no difference in survival between ever-smokers and never-smokers; moreover, smoking status was not a significant prognostic factor. ${ }^{17}$ Furthermore, other reports found no survival difference between current and never smokers, and current smoking was not a significant prognostic factor. ${ }^{8,18}$ The results of the present study show overall poor survival among ever-smokers compared to never-smokers; however, ever-smoking did not have prognostic significance after adjusting for covariates. Current smoking, rather than ever-smoking, was an independent risk factor of a poor prognosis. Several reasons for these discrepancies exist. Among them, demographic differences in the study population, including ethnicity and stage of lung cancer, are important. The prognosis of surgical and nonsurgical patients according to smoking status is expected to differ. In fact, most studies of surgical patients report a poor prognosis of smokers or smoking as a significant prognostic factor. ${ }^{7,16,19-21}$ Otherwise, studies that reported no impact of smoking included all stages of lung cancer, with more than $70 \%$ of patients with stage III or higher disease. ${ }^{8,17}$ The methods of determining and adjusting for various confounding factors also differed among the many studies.

Lung cancer in never-smokers accounts for about 10-15\% of all cancers. ${ }^{22,23}$ Adenocarcinoma is the predominant histologic type, and females are more affected than males. ${ }^{24-27}$ In the present study, more than $80 \%$ of the subjects had the adenocarcinoma histological type, and females accounted for $85.9 \%$ of the never-smokers with lung cancer. Exposure to biomass or passive smoke may contribute to the high percentage of never-smoking women with adenocarcinoma. It is unclear why the proportion of never-smokers with stage IV disease was almost half of all never-smokers, and why neversmokers were significantly younger than ever-smokers in the present study population. We excluded lung cancer presenting as GGN, which was mostly adenocarcinoma in neversmokers, because the tumor biology is thought to be different in these cases. Despite the high proportion of patients with stage IV disease and the exclusion of GGN, the overall survival of never-smokers was significantly better.

Sputum was the only symptom more common at presentation in ever-smokers. Irrespective of other symptoms being comparable between the groups, never-smokers were significantly more asymptomatic. Considering this phenomenon, together with the advanced disease stage in never-smokers, a method of detecting asymptomatic lung cancer earlier in never-smokers is needed to improve the prognosis.

Lung cancer is a common comorbidity and a major cause of death in patients with chronic obstructive pulmonary disease (COPD)..$^{28,29}$ Among subjects in the present study, COPD coexisted with NSCLC in $35.5 \%$ of all enrolled patients and $50.2 \%$ of ever-smokers. The high incidence of COPD in ever-smokers is thought to be the reason for the predominance of male, lower $\mathrm{FEV}_{1}$ (\% predicted), and a relative paucity of stage I disease and adenocarcinoma histology compared to never-smokers.

Previous studies of the impact of ILD on the survival of patients with lung cancer found that patients with both ILD and lung cancer had shorter overall survival rates than those without ILD. Furthermore, ILD was a significant predictor of a poor prognosis. ${ }^{30-32}$ In the present study, ILD was present in 11 patients $(3.5 \%)$ at the time of diagnosis, and was a poor prognostic factor after multivariate analysis, as in previous reports. Thus, the presence of ILD should be considered an important factor at the time of diagnosis and treatment.

Limitations of this study are as follows: (i) the cause of death could not be identified, thus the cause specific mortality could not be evaluated because this is a retrospective study; (ii) the number of enrolled patients was relatively small as many patients with NSCLC were excluded because of unidentifiable smoking history; and (iii) a history of exposure to the passive cigarette smoke and biomass smoke could not investigated.

\section{Conclusion}

In conclusion, ever-smokers had poorer survival rates than never-smokers, and current smoking was a significant prognostic factor of a poor prognosis in the present study population. Further efforts towards smoking cessation are needed, not only to decrease the incidence of lung cancer, but also to increase the survival of patients with NSCLC. 


\section{Disclosures}

No authors report any conflict of interest.

\section{References}

1 Ferlay J, Shin HR, Bray F, Forman D, Mathers C, Parkin DM. Estimates of worldwide burden of cancer in 2008: GLOBOCAN 2008. Int J Cancer J Int Cancer 2010; 127: 2893-917.

2 Jemal A, Bray F, Center MM, Ferlay J, Ward E, Forman D. Global cancer statistics. (Erratum in CA Cancer J Clin 2011; 61: 134.) CA Cancer J Clin 2011; 61 (2): 69-90.

3 Agudo A, Bonet C, Travier N et al. Impact of cigarette smoking on cancer risk in the European prospective investigation into cancer and nutrition study. J Clin Oncol 2012; 30: 4550-7.

4 Gandini S, Botteri E, Iodice S et al. Tobacco smoking and cancer: a meta-analysis. Int J Cancer 2008; 122: 155-64.

5 Ezzati M, Lopez AD. Estimates of global mortality attributable to smoking in 2000. Lancet 2003; 362 (9387): 847-52.

6 Ferketich AK, Niland JC, Mamet R et al. Smoking status and survival in the national comprehensive cancer network non-small cell lung cancer cohort. Cancer 2013; 119 (4): 847-53.

7 Sardari Nia P, Weyler J, Colpaert C, Vermeulen P, Van Marck E, Van Schil P. Prognostic value of smoking status in operated non-small cell lung cancer. Lung Cancer 2005; 47: 351-9.

8 Meguid RA, Hooker CM, Harris J et al. Long-term survival outcomes by smoking status in surgical and nonsurgical patients with non-small cell lung cancer: comparing never smokers and current smokers. Chest 2010; 138: 500-9.

9 The Surgeon General's 1989 Report on Reducing the Health Consequences of Smoking: 25 Years of Progress. MMWR Morb Mortal Wkly Rep 1989; 38 (Suppl 2): 1-32.

10 Ezzati M, Lopez AD. Regional, disease specific patterns of smoking-attributable mortality in 2000. Tob Control 2004; 13: 388-95.

11 Parsons A, Daley A, Begh R, Aveyard P. Influence of smoking cessation after diagnosis of early stage lung cancer on prognosis: systematic review of observational studies with meta-analysis. BMJ 2010; 340: b5569.

12 Ebbert JO, Williams BA, Sun Z et al. Duration of smoking abstinence as a predictor for non-small-cell lung cancer survival in women. Lung Cancer 2005; 47: 165-72.

13 Wakai K, Marugame T, Kuriyama S et al. Decrease in risk of lung cancer death in Japanese men after smoking cessation by age at quitting: pooled analysis of three large-scale cohort studies. Cancer Sci 2007; 98: 584-9.

14 Zhou W, Heist RS, Liu G et al. Smoking cessation before diagnosis and survival in early stage non-small cell lung cancer patients. Lung Cancer 2006; 53: 375-80.

15 Tammemagi CM, Neslund-Dudas C, Simoff M, Kvale P. Smoking and lung cancer survival: the role of comorbidity and treatment. Chest 2004; 125: 27-37.
16 Hanagiri T, Sugio K, Mizukami M et al. Significance of smoking as a postoperative prognostic factor in patients with non-small cell lung cancer. J Thorac Oncol 2008; 3: 1127-32.

17 Toh CK, Wong EH, Lim WT et al. The impact of smoking status on the behavior and survival outcome of patients with advanced non-small cell lung cancer: a retrospective analysis. Chest 2004; 126: 1750-6.

18 Subramanian J, Velcheti V, Gao F, Govindan R. Presentation and stage-specific outcomes of lifelong never-smokers with non-small cell lung cancer (NSCLC). J Thorac Oncol 2007; 2: 827-30.

19 Chen J, Jiang R, Garces YI et al. Prognostic factors for limitedstage small cell lung cancer: a study of 284 patients. Lung Cancer 2010; 67: 221-6.

20 Yoshino I, Kawano D, Oba T, Yamazaki K, Kometani T, Maehara Y.Smoking status as a prognostic factor in patients with stage I pulmonary adenocarcinoma. Ann Thorac Surg 2006; 81: 1189-93.

21 Fujisawa T, Iizasa T, Saitoh Y et al. Smoking before surgery predicts poor long-term survival in patients with stage I non-small-cell lung carcinomas. J Clin Oncol 1999; 17: 2086-91.

22 Siegel R, Ward E, Brawley O, Jemal A. Cancer statistics, 2011: the impact of eliminating socioeconomic and racial disparities on premature cancer deaths. CA Cancer J Clin 2011; 61:212-36.

23 Sun S, Schiller JH, Gazdar AF. Lung cancer in never smokers a different disease. Nat Rev Cancer 2007; 7: 778-90.

24 Govindan R. Lung cancer in never smokers: a new hot area of research. Lancet Oncol 2010; 11: 304-5.

25 Couraud S, Zalcman G, Milleron B, Morin F, Souquet PJ. Lung cancer in never smokers - a review. Eur J Cancer 2012; 48: 1299-311.

26 Subramanian J, Govindan R. Lung cancer in never smokers: a review. J Clin Oncol 2007; 25: 561-70.

27 Samet JM, Avila-Tang E, Boffetta $\mathrm{P}$ et al. Lung cancer in never smokers: clinical epidemiology and environmental risk factors. Clin Cancer Res 2009; 15: 5626-45.

28 Anthonisen NR, Skeans MA, Wise RA, Manfreda J, Kanner RE, Connett JE. The effects of a smoking cessation intervention on 14.5-year mortality: a randomized clinical trial. Ann Intern Med 2005; 142: 233-9.

29 Decramer M, Janssens W, Miravitlles M. Chronic obstructive pulmonary disease. Lancet 2012; 379 (9823): 1341-51.

30 Miyazaki K, Satoh H, Kurishima K et al. Interstitial lung disease in patients with small cell lung cancer. Med Oncol 2010; 27: 763-7.

31 Miyazaki K, Satoh H, Kurishima K et al. Impact of interstitial lung disease on survival for patients with non-small cell lung cancer. Anticancer Res 2009; 29: 2671-4.

32 Togashi Y, Masago K, Handa T et al. Prognostic significance of preexisting interstitial lung disease in Japanese patients with small-cell lung cancer. Clin Lung Cancer 2012; 13: 304-11. 